\title{
Dietary pattern, a modifiable risk factor that can be easily assessed for atherosclerosis vascular disease prevention in clinical practice
}

\author{
Guillaume Mahe ${ }^{1, *}$, Marie Carsin ${ }^{2}$, Maya Zeeny ${ }^{3}$ and Jean-Paul De Bosschere 2 \\ 'Laboratoire d'Explorations Fonctionnelles Vasculaires, CHU Angers, 4 rue Larrey, F-49933 Angers Cedex 9, \\ France: ${ }^{2}$ Department de Médecine Générale, Université de Rennes, Rennes, France: ${ }^{3}$ Department de Nutrition \\ et Diététique, Université Saint-Joseph, Beirut, Lebanon
}

Submitted 26 August 2009: Accepted 22 April 2010: First published online 6 July 2010

\begin{abstract}
Objectives: Nutrition is one of the modifiable risk factors of atherosclerosis vascular diseases (VD). We aimed to (i) evaluate the dietary patterns associated with VD in clinical practice using a validated FFQ; and (ii) determine potential independent sociodemographic and behavioural factors that are involved in such dietary patterns. The FFQ determined the vascular dietary score (VDS; ranges from -17 to 19) for each subject.

Design: Cross-sectional study.

Setting: A general practitioner's (GP) office in 2009.

Subjects: A total of 250 French subjects (18-84 years old).

Results: A total of $21 \%$ had a favourable vascular diet (VDS $\geq 8$ ), $79 \%$ needed to improve their diet (VDS $<8$ ) and $21 \%$ had a risky vascular diet (VDS $\leq-1$ ). A stepby-step multivariate linear regression analysis with stepwise selection was performed using the VDS as a dependent variable. Significant variables were: age $(\beta=0 \cdot 495$, $P<0 \cdot 0001)$, men $(\beta=-0.282, \quad P<0 \cdot 0001)$, 'sport $\geq 1 \mathrm{~h} /$ week' $(\beta=0.253, \quad P=$ $0 \cdot 001)$, 'walking $20 \mathrm{~min} / \mathrm{d}$ ' $(\beta=0 \cdot 161, P=0 \cdot 012)$, 'former smoker' $(\beta=0 \cdot 118$, $P=0 \cdot 029)$, previous nutritional advice $(\beta=0 \cdot 105, P=0 \cdot 049)$, 'alcohol $\geq 20 \mathrm{~g} / \mathrm{d}$ ' $(\beta=-0 \cdot 216, P<0 \cdot 0001)$ and 'primary school' $(\beta=-0 \cdot 156, P=0 \cdot 010)$. The $R^{2}$ coefficient of this model was $0.347(P<0 \cdot 0001)$. In all, $88.7 \%$ of the subjects found the evaluation very interesting and $89 \cdot 6 \%$ believed that the GP should perform it. Conclusions: Simple dietary assessment for VD prevention can be easily performed in clinical practice to allow physicians to give objective and rapid advice for each patient. Age, educational status, alcohol consumption, gender and physical activity are associated with the VDS. Compliance with such evaluation was found to be very high, which should encourage larger dietary screening in the population in order to reduce the impact of VD.
\end{abstract}

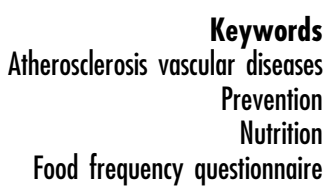

Vascular diseases (VD) including CHD, stroke, hypertension and peripheral artery disease (PAD) are major health and economic problems in Western countries ${ }^{(1)}$. CHD, stroke and PAD share many common risk factors: nonmodifiable risk factors, such as age and gender, and modifiable risk factors, such as smoking, dyslipidaemia, obesity and diabetes. Over the past few years, diet and lifestyle have been identified as modifiable risk factors in VD, especially in VD due to atherosclerosis ${ }^{(2-4)}$. Many studies have shown that dietary patterns play a major role in the development and prevention of $\mathrm{VD}$, as in $\mathrm{CHD}^{(5-10)}$. Dietary patterns also seem to play a role in ischaemic stroke $\mathrm{e}^{(3,11)}$ and increase the prevalence of PAD ${ }^{(12)}$. Thus, both dietary assessment and dietary management appear to be essential to limit the impact of VD due to atherosclerosis ${ }^{(13)}$.
Unfortunately, dietary assessment remains a difficult challenge. First, physicians often have insufficient knowledge about food composition and how to give dietary advice ${ }^{(14)}$. Furthermore, most of the available tools (diet interviews, diet records, large FFQ) used to evaluate an individual diet are too complicated and time consuming for routine clinical practice and population screening. However, the first step to take preventive action is to develop useful validated tools for measuring risk factors in clinical practice. Many authors have suggested using short FFQ to evaluate characteristic food groups known to play roles in specific diseases ${ }^{(15-17)}$. Laviolle et $_{\text {al }}{ }^{(16)}$ previously validated a fourteen-item FFQ for atherosclerosis VD prevention in a French population. This FFQ did not assess an exhaustive diet but evaluated dietary patterns known to be associated with CHD, 
ischaemic stroke and carotid atherosclerosis ${ }^{(16,18)}$. It provides scores for characteristic food groups involved in atherosclerosis diseases (scores for SFA, MUFA, $n$-3 PUFA and for fruit and vegetables (F\&V)) as well as a global nutritional score ${ }^{(16)}$. For a given subject, this global nutritional score is named the 'vascular dietary score' $(\text { VDS })^{(17)}$. Based on the calculation method ${ }^{(16)}$ and the literature $^{(3,5,6)}$, a high score means a favourable diet against VD, whereas a low score means a diet associated with VD considered as a risky vascular diet ${ }^{(16,18)}$. Such specific diet screening for VD could be useful not only for each subject at the individual level but also for large national recommendations about nutrition and VD prevention ${ }^{(13,17)}$.

Previous epidemiological studies, but not in a general practitioner's (GP) office, showed that socio-economic, demographic and behavioural factors in part explained lifestyles and dietary patterns ${ }^{(19-22)}$. However, they did not study the relationship of these factors with a specific diet involved in $\mathrm{VD}$, which precludes screening the population that had a risky vascular diet. A better knowledge of these factors may help to improve global information and political action about nutrition and VD.

The aim of the present study was first to assess, in clinical practice, the dietary pattern of a population of French subjects (VDS) using a previously validated $\mathrm{FFQ}^{(16)}$. Second, we investigated the relationship of socio-economic, demographic and behavioural factors with the VDS. Finally, we evaluated the acceptance and the interest of subjects in this dietary assessment.

\section{Materials and methods}

\section{Population}

A cross-sectional study was conducted in a French GP's office. Subjects over 18 years of age were consecutively included. An investigator invited each subject when they attended for their regular check-up to answer a dietary questionnaire before consultation. All of the participants were Caucasian residents and gave their informed consent. The present study was performed in accordance with French medical laws and received the ethics committee agreement of the University Hospital of Angers.

\section{Dietary assessment}

We used a short FFQ developed for food assessment in CHD prevention and in ischaemic stroke ${ }^{(16)}$. This FFQ was previously validated against biomarkers and a $7 \mathrm{~d}$ dietary history, which reflect long-term dietary intake ${ }^{(16)}$. This semi-quantitative FFQ is constructed with fourteen questions selected to give information about the intake of food groups likely to influence CHD risk. Six questions explored the SFA intake from 'cheese', 'red meat', 'delicatessen', 'salted pies and pizzas', 'cookies, cakes and pastries' and 'butter'. Five questions explored the vegetable MUFA, the $n-6$ and $n-3$ PUFA intakes from vegetable fats, fish and nuts. Three questions explored the F\&V intake. A specific score was calculated for SFA, MUFA, $n-6$ PUFA, $n-3$ PUFA and $\mathrm{F} \& \mathrm{~V}$. A negative score of 17 points was attributed to SFA consumption, which represents an unfavourable consumption for $\mathrm{VD}^{(6,9)}$. A positive score of 19 points was achieved with vegetable MUFA, $n-3$ PUFA and F\&V, which represent favourable food groups against $\mathrm{VD}^{(5,6,23)}$. The score for vegetable MUFA ( $0-4$ points) corresponded to a reported consumption ranging from $<6$ to $>24 \mathrm{~g} / \mathrm{d}$ with an increment of $6 \mathrm{~g} /$ score point. The score for $n-3$ PUFA ( $0-8$ points) corresponded to a reported consumption ranging from $<0.30$ to $>2 \cdot 4 \mathrm{~g} / \mathrm{d}$ with an increment of $0.3 \mathrm{~g} / \mathrm{score}$ point. The score for $\mathrm{F} \& \mathrm{~V}$ ranged from 0 to 7 points. Eight points $(1.5 \mathrm{~g} /$ score point) were attributed to $n-6$ PUFA consumption, which was not included in the VDS but was used to estimate the $n$ - 6 PUFA: $n-3$ PUFA ratio. Lastly, a global dietary score called VDS was calculated as $(\mathrm{MUFA}+n$-3 PUFA $+\mathrm{F} \& \mathrm{~V})-(\mathrm{SFA})$ scores (Fig. 1). It gives an estimation of the dietary pattern graded from -17 to +19 . The higher the score, the more favourable was the dietary pattern.

The validity against dietary history was previously assessed with Spearman's correlation coefficients, which ranged from $0.47(\mathrm{~F} \& \mathrm{~V})$ to 0.63 (PUFA/SFA; all $P<0.05)$, with a mean value of 0.54 . The biomarker-based validity using Spearman's correlation coefficients varied from $0 \cdot 21$ (SFA) to 0.53 ( $n$-3 PUFA; all $P<0.05$ ), with a mean value of $0 \cdot 35$. Reproducibility assessed by the intra-class correlation coefficient ranged from $0 \cdot 71$ (MUFA) to 0.93 (VDS), with a mean value of $0 \cdot 81^{(16)}$. Please refer to the validation paper for more information and access to the whole questionnaire $^{(16)}$. The administration of this FFQ needed 5-10 min. We used a computerized questionnaire version (Microsoft ${ }^{\circledR}$ Excel 2000; Microsoft Corp, Redmond, WA, USA) to limit errors of data capture and immediately give scores and dietary advice to subjects. Although a clinical cut-off has not yet been determined, based on the results of previous studies ${ }^{(16,18)}$, a VDS of $\geq 8$ was considered as a favourable vascular diet and a VDS of $<8$ was considered as a diet that needed improvement ${ }^{(16,24)}$. Indeed, a VDS of $\geq 8$ can be considered as a favourable diet against VD due to the score calculation method ${ }^{(16)}$ and the literature ${ }^{(3,5,6,8,23)}$. A VDS of $\geq 8$ corresponds to a high consumption of $F \& V$, MUFA, $n-3$ PUFA and a low consumption of SFA ${ }^{(16)}$. Furthermore, a VDS of +7 was previously found in patients between 6 months and 3 years after completing a cardiovascular rehabilitation programme (during which they had received nutritional advice $)^{(24)}$. A VDS $\leq-1$ was considered a risky vascular diet because a VDS of -1 was previously found to be associated with acute CHD and a worse VDS was found in ischaemic stroke patients and carotid atherosclerosis ${ }^{(16,18,24)}$.

\section{Statistics}

All data were expressed as the mean with their standard errors for continuous variables or number and percentage 


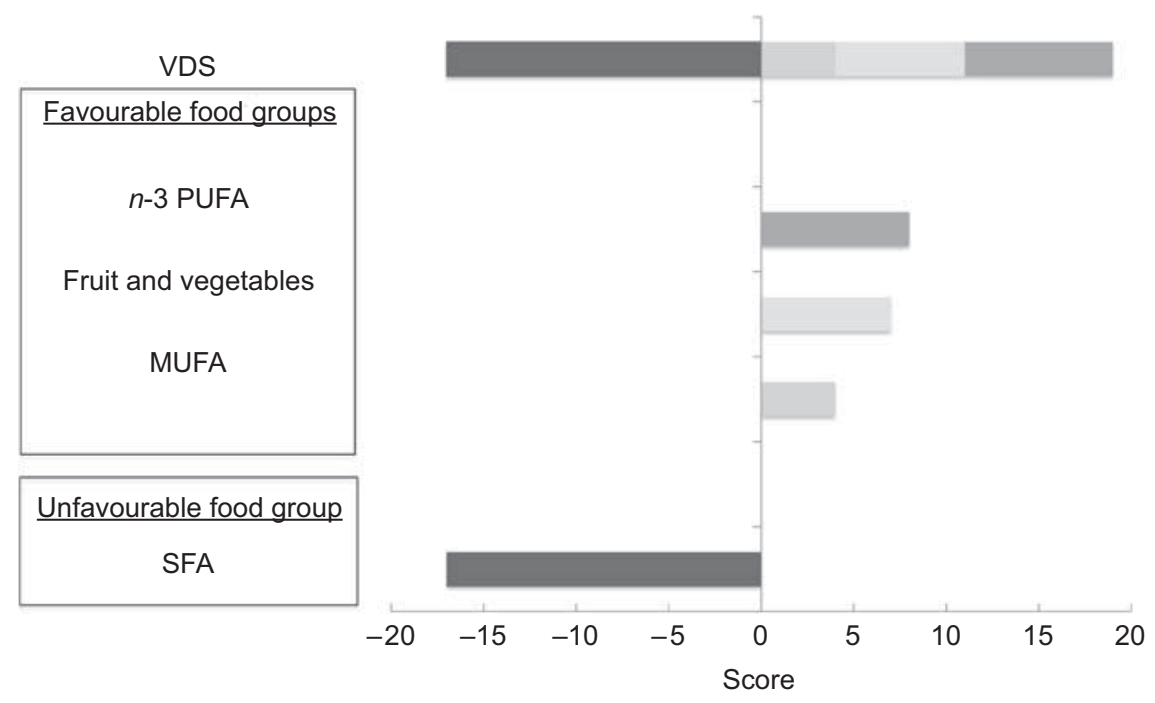

Fig. 1 Calculation method of the vascular dietary score (VDS)

for categorical variables. A step-by-step multivariate linear regression analysis with stepwise selection was performed using the VDS as the dependent variable. Dummy variables were used to treat the qualitative variables ${ }^{(25)}$. The $P$ value for explanatory parameters to enter and stay in the model was set at $0 \cdot 10$. All variables presented in Table 1 were tested with univariate analysis for association with the VDS. According to the literature ${ }^{(20,22)}$ and after univariate regressions ${ }^{(26)}$, the fifteen explanatory parameters included in the model were: age, gender (men), BMI, physical activity represented by 'walking $20 \mathrm{~min} / \mathrm{d}$ ' and by 'sport $\geq 1 \mathrm{~h} /$ week', alcohol consumption represented by 'alcohol $10 \mathrm{~g} / \mathrm{d}$ ' and 'alcohol $\geq 20 \mathrm{~g} / \mathrm{d}$ ', smoking status represented by 'former smoker' and 'smoker', educational level represented by 'primary school' and by 'university or equivalent', marital status represented by 'living in a couple', fact of 'having child or children', history of previous nutritional advice and 'treatment taking'. The occupational categories represented by 'farmers', 'craftsmen, self-employed, storekeepers', 'executives, intellectuals', 'intermediate professions', 'employees', 'manual workers', 'retired' and 'unemployed' were not included in the model because there was collinearity with educational status and few subjects in some categories. In a multivariate analysis, a positive or negative $\beta$ value means a positive or inverse relationship between the dependent variable and an explanatory parameter, respectively. $\beta$ coefficients were normalized to percentage values when significant, and are an estimation of the relative participation of the explanatory parameter to the variable to be explained by the model. A probability level of $P<0.05$ was used to indicate statistical significance. The Statistical Package for Social Sciences statistical software package version $16 \cdot 0$ (SPSS Inc., Chicago, IL, USA) was used for all statistical analyses.

\section{Sample size estimation}

To test different variables in a multivariate linear regression, ten subjects for each of the variables that were tested were needed. In the present study, fifteen variables were tested. Therefore, a minimum of 150 subjects was required ${ }^{(27)}$.

\section{Results}

During the inclusion period, fourteen subjects did not agree to answer the questionnaire. Two hundred and fifty subjects (18-84 years old) were included in the present study with a majority of women $(63 \cdot 6 \%)$. The mean age was 53 (SE 16) years in men and 49 (SE 18) years in women. Subject characteristics are summarized in Table 1.

Figure 2 presents the distribution of the VDS in the studied population. Mean VDS was $3 \cdot 3$ (SE 4.8). Positive dietary scores were $4 \cdot 6(\mathrm{se} 1 \cdot 7)$ for $\mathrm{F} \& \mathrm{~V}, 1 \cdot 1(\mathrm{sE} 0 \cdot 9)$ for MUFA, $2 \cdot 1$ (sE $1 \cdot 7$ ) for $n$-3 PUFA. The negative dietary score represented by SFA score was $4 \cdot 5$ (SE 2.6). The $n-6$ PUFA: $n$-3 PUFA ratio was $8 \cdot 3$ (SE $8 \cdot 1$ ).

Fifty-three subjects $(21 \%)$ had a favourable vascular diet with a VDS of $10 \cdot 0(\operatorname{SE~} 0 \cdot 2)$, whereas fifty-three had a risky vascular diet with a VDS of $-3 \cdot 3$ (SE 0.3). Dietary habits of both groups are detailed in Table 2 .

Results for the multivariate linear regression model found eight variables for which $\beta$ reached significance. A positive significant association was found for five variables: age $(\beta=0 \cdot 495, P<0 \cdot 0001)$, 'sport $\geq 1 \mathrm{~h} /$ week' $(\beta=0.253, \quad P=0 \cdot 001)$, 'walking $20 \mathrm{~min} / \mathrm{d}$ ' $(\beta=0 \cdot 161$, $P=0 \cdot 012)$, 'former smoker' $(\beta=0 \cdot 118, P=0 \cdot 029)$ and previous nutritional advice $(\beta=0 \cdot 105, P=0 \cdot 049)$. A negative significant association was found for three variables: men $(\beta=-0 \cdot 282, P<0 \cdot 0001)$, 'alcohol $\geq 20 \mathrm{~g} / \mathrm{d}$ ' $(\beta=-0 \cdot 216, P<0 \cdot 0001)$ and primary school $(\beta=-0 \cdot 156$, $P=0 \cdot 010)$. The $R^{2}$ coefficient of the model with these 
Table 1 General characteristics of the population

\begin{tabular}{|c|c|c|}
\hline & \multicolumn{2}{|c|}{ Population ( $n$ 250) } \\
\hline & Mean & SE \\
\hline \multirow{3}{*}{$\begin{array}{l}\text { Age (years) } \\
\text { BMl }\left(\mathrm{kg} / \mathrm{m}^{2}\right)\end{array}$} & $50 \cdot 5$ & $17 \cdot 0$ \\
\hline & $25 \cdot 4$ & $5 \cdot 4$ \\
\hline & $n$ & $\%$ \\
\hline Men & 91 & $36 \cdot 4$ \\
\hline \multicolumn{3}{|l|}{ Smoking status } \\
\hline Non-smokers* & 156 & $62 \cdot 4$ \\
\hline Former smokers & 37 & $14 \cdot 8$ \\
\hline Smokers & 57 & $22 \cdot 8$ \\
\hline \multicolumn{3}{|l|}{ Regular physical activity } \\
\hline None $^{*}$ & 72 & $28 \cdot 8$ \\
\hline Walking $(20 \mathrm{~min} / \mathrm{d})$ & 79 & $31 \cdot 6$ \\
\hline Sport ( $\geq 1 \mathrm{~h} /$ week) & 99 & $39 \cdot 6$ \\
\hline \multicolumn{3}{|l|}{ Education level } \\
\hline Primary school & 44 & $17 \cdot 6$ \\
\hline Secondary school* & 117 & $46 \cdot 8$ \\
\hline University or equivalent & 89 & $35 \cdot 6$ \\
\hline \multicolumn{3}{|l|}{ Occupational categories (one datum missing) } \\
\hline Farmers & 9 & $3 \cdot 6$ \\
\hline Craftsmen, self-employed, storekeepers & 17 & $6 \cdot 8$ \\
\hline Executives, intellectuals & 20 & $8 \cdot 1$ \\
\hline Intermediate professions* & 46 & $18 \cdot 5$ \\
\hline Employees & 27 & $10 \cdot 8$ \\
\hline Manual workers & 41 & $16 \cdot 5$ \\
\hline Retired & 72 & $28 \cdot 9$ \\
\hline Unemployed & 17 & $6 \cdot 8$ \\
\hline \multicolumn{3}{|l|}{ Marital status (two data missing) } \\
\hline Living with a partner & 213 & $85 \cdot 9$ \\
\hline Living alone & 35 & $14 \cdot 1$ \\
\hline \multicolumn{3}{|l|}{ Alcohol consumption } \\
\hline Occasional* $^{*}$ & 203 & $81 \cdot 2$ \\
\hline $10 \mathrm{~g} / \mathrm{d}$ & 33 & $13 \cdot 2$ \\
\hline$\geq 20 \mathrm{~g} / \mathrm{d}$ & 14 & $5 \cdot 6$ \\
\hline Treated & 123 & $49 \cdot 2$ \\
\hline Anti-hypertensive & 57 & $22 \cdot 8$ \\
\hline Anti-cholesterol & 56 & $22 \cdot 4$ \\
\hline Anti-diabetes & 9 & $3 \cdot 6$ \\
\hline Anti-platelet & 14 & $5 \cdot 6$ \\
\hline Anti-coagulant & 9 & $3 \cdot 6$ \\
\hline Anti-thyroid & 7 & $2 \cdot 8$ \\
\hline Oral contraceptive & 39 & $15 \cdot 6$ \\
\hline
\end{tabular}

'Walking $20 \mathrm{~min} / \mathrm{d}$ ' meant 'light-to-moderate physical activity'. 'Sport $\geq 1 \mathrm{~h} /$ week' meant 'moderate-to-vigorous physical activity'. Data are expressed as mean with their standard errors for continuous variables. Number of subjects $(n)$ and percentages are reported for categorical variables.

*Variable reference for univariate analysis.

eight variables was $0 \cdot 347(P<0 \cdot 0001)$. None of the other variables reached statistical significance for $\beta$ ('living in a couple', 'having a child or children', 'treatment taking', 'smoker', BMI, 'university or equivalent', 'alcohol $10 \mathrm{~g} / \mathrm{d}$ '). The histogram of normalized significant $\beta$ values estimated from the model is presented in Fig. 3.

None of the subjects found the dietary assessment with this FFQ uninteresting. Twenty-eight subjects (11.3\%) found it mildly interesting and $221(88 \cdot 7 \%)$ found it very interesting (one datum missing). Two hundred and twentyfour subjects (89.6\%) estimated that dietary assessment should be performed by the GP, whereas twenty-six others $(10 \cdot 4 \%)$ thought that other medical professionals should perform it, such as nurses or nutritionists.

\section{Discussion}

To the best of our knowledge, the present study is the first dietary evaluation for VD prevention using an extremely short validated FFQ performed in a GP's office. We show that this FFQ with its calculated scores is a simple and fast tool to perform vascular dietary assessment for subjects in clinical practice. Moreover, the different scores representing different food groups give a rapid and global view of dietary habits for each subject and for each food group (SFA, MUFA, F\&V, n-3 PUFA and n-6 PUFA) known to be associated with VD due to atherosclerosis ${ }^{(3,5,6,9,23)}$. The GP or physician who performs the assessment can immediately evaluate (and communicate to the subject) every subject's scores, especially the VDS that could be considered as 'the nutritional risk of atherosclerosis VD'. Then, the physician can give specific nutritional advice on bad scores without wasting time. The subject additionally receives his scores, which motivates him to improve his diet. A follow-up can easily be performed with such a tool because this FFQ had good reproducibility as previously shown ${ }^{(16)}$.

In the present population, only $21 \%$ had a favourable vascular diet represented by a VDS of $\geq 8$. Drewnowski et $a{ }^{(20)}$ found that only $3 \%$ of the SU.VI.MAX population had 'good diets' applying the original 1995 Health Eating Index (HEI) developed by the United States Department of Agriculture $^{(28)}$. Although the mean age of the SU.VI.MAX population (49 years old) was quite similar to our population ( 51 years old), these differences can be explained by different reasons. First, the HEI did not evaluate specific diet for VD due to atherosclerosis ${ }^{(29)}$. Moreover, the SU.VI.MAX population had fewer women $(56.7 \%)$ than our population $(63.6 \%)$ and women are known to have better eating habits than men ${ }^{(30)}$. To complete these explanations, data of the SU.VI.MAX population were approximately collected 15 years ago. During this period, dietary habits and food composition patterns have changed ${ }^{(31)}$. Furthermore, since 2001, a nutrition and health programme, Programme National Nutrition Santé (PNNS), including diet and physical activity recommendations has been carried out in France and disseminated widely to the general population ${ }^{(32)}$. This can also explain why we found that $79 \%$ of our population needed to improve their diet as opposed to $89 \%$ of the SU.VI.MAX studied population. We also showed that $21 \%$ of the present population had a VDS that was previously found to be associated with CHD, ischaemic stroke and carotid atherosclerosis ${ }^{(16,18,24)}$. People classified as having a risky vascular diet consumed $73 \%$ more SFA on average than those classified as having a favourable vascular diet. A high consumption of SFA has been found to be associated with a higher risk of atherosclerosis $\mathrm{VD}^{(9,33)}$. Moreover, lower consumptions of protective food groups (F\&V, MUFA, n-3 PUFA) was found in the risky vascular diet. These protective food 


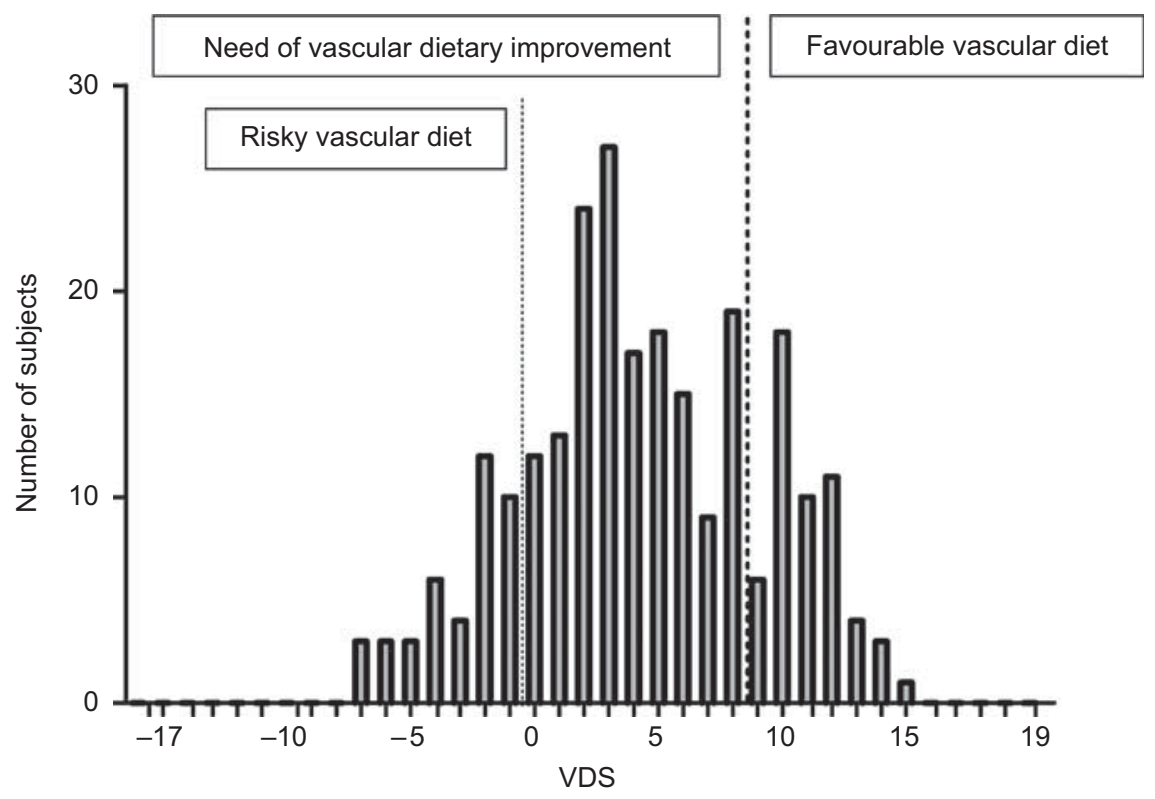

Fig. 2 Distribution of the vascular dietary score (VDS) in the studied population (250 subjects). Need of vascular dietary improvement is defined by a VDS $<8$. Optimal dietary score is a VDS $\geq 8$. Risky vascular dietary is a VDS $\leq-1$

Table 2 Dietary characteristics of subjects with a favourable diet against vascular disease and subjects with a risky vascular diet

\begin{tabular}{|c|c|c|c|c|c|c|c|c|c|c|c|c|}
\hline & \multicolumn{2}{|c|}{ SFA } & \multicolumn{2}{|c|}{$\mathrm{F} \& \mathrm{~V}$} & \multicolumn{2}{|c|}{ MUFA } & \multicolumn{2}{|c|}{$n$-3 PUFA } & \multicolumn{2}{|c|}{$n-6$ PUFA: $n-3$ PUFA } & \multicolumn{2}{|c|}{ VDS } \\
\hline & Mean & $\mathrm{SE}$ & Mean & SE & Mean & $\mathrm{SE}$ & Mean & SE & Mean & SE & Mean & SE \\
\hline $\begin{array}{l}\text { Subjects with a favourable diet against } \\
\text { vascular diseases }(n 33)\end{array}$ & $2 \cdot 0$ & $0 \cdot 2$ & $5 \cdot 9$ & $0 \cdot 1$ & $1 \cdot 9$ & $0 \cdot 1$ & $4 \cdot 2$ & $0 \cdot 2$ & $4 \cdot 0$ & $0 \cdot 4$ & $10 \cdot 0$ & $0 \cdot 2$ \\
\hline Subjects with a risky vascular diet ( $n$ 33) & $7 \cdot 3$ & $0 \cdot 3$ & $2 \cdot 7$ & $0 \cdot 2$ & 0.5 & $0 \cdot 1$ & $0 \cdot 8$ & $0 \cdot 1$ & $16 \cdot 3$ & $2 \cdot 2$ & $-3 \cdot 3$ & 0.3 \\
\hline
\end{tabular}

F\&V, fruit and vegetables; VDS, vascular dietary score calculated as (MUFA + n-3 PUFA + F\&V) - SFA.

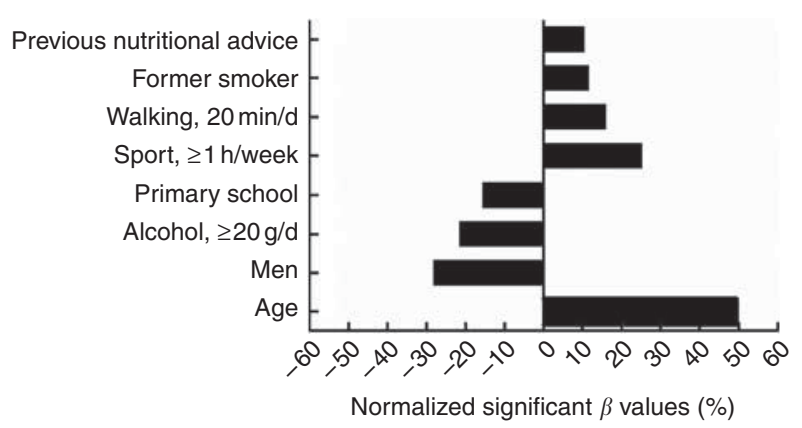

Fig. 3 Normalized significant $\beta$ values (\%) resulting from the model to explain the vascular dietary score (VDS). A positive $\beta$ value means a positive association with a high VDS. A negative $\beta$ value means an inverse association with a high VDS. Significant $\beta$ value: $P<0.05$. 'Walking $20 \mathrm{~min} / \mathrm{d}$ ' meant 'light-to-moderate physical activity'; 'sport $\geq 1 \mathrm{~h} /$ week' meant 'moderate-to-vigorous physical activity'; non-significant $\beta$ values are not presented

groups have been repeatedly involved in the risk reduction of atherosclerosis $\mathrm{VD}^{(8,12,33,34)}$. Fung et $a l^{(11)}$ suggested that a dietary habit typified by higher intakes of red and processed meats, refined grains and sweets and desserts may increase ischaemic stroke risk, whereas a diet higher in $\mathrm{F} \& \mathrm{~V}$, fish and whole grains may protect against stroke. These results were confirmed in the INTERHEART Study by Iqbal et $a l^{(8)}$. These authors observed an inverse association between a 'prudent diet' characterized by a diet high in F\&V and acute myocardial infarction, with higher levels being protective ${ }^{(8)}$. Moreover, Lane et al. $^{(12)}$ found that improved nutrition is associated with a reduced prevalence of PAD in the US population. Indeed, a higher consumption of specific nutrients, including antioxidants (vitamins $\mathrm{A}, \mathrm{C}$ and $\mathrm{E}$ ), vitamin $\mathrm{B}_{6}$, fibre, folate and $n$-3 PUFA, has a significant protective effect, irrespective of traditional cardiovascular risk factors ${ }^{(12)}$. In secondary prevention of CVD, metaanalyses and systematic reviews found that reducing SFA associated with the addition of Mediterranean dietary advice reduces morbidity in patients with $\mathrm{CVD}^{(9)}$. Lastly, Mozaffarian et al. ${ }^{(10)}$ have even suggested that consuming PUFA in place of SFA reduces CHD events in randomized control trials.

According to the nutritional recommendations of the French PNNS, our study confirmed the results of two other French studies in which subjects recruited through a media campaign had an unsatisfactory diet ${ }^{(35,36)}$. In our 
study, only $11.6 \%$ had an F\&V score corresponding to five servings per day. Estimations of MUFA, $n-3$ PUFA and $n$-6 PUFA intake for the whole studied population were 6.6, 0.6 and $3.4 \mathrm{~g} / \mathrm{d}$, respectively. This protective intake was lower than that expected in the French population $^{(37)}$

Many factors were found to affect the VDS. Being a young man, consuming $\geq 20$ g of alcohol per day, without doing regular physical activity and only with a primaryschool level of education was associated with a poor vascular diet (low VDS). In contrast, being an old woman practising sports with no alcohol consumption and a university-level education was associated with a better vascular diet (high VDS). Previous studies have shown that aged subjects consume less red meat and more F\&V, not only in France but also in other European countries $^{(20,21,38,39)}$, whereas young people eat more takeaway foods and refined products and sweets ${ }^{(40-42)}$. Furthermore, ageing induces physiological modifications (slower gastric emptying, changes in the chemosensory perceptual systems with a decline in gustatory and olfactory

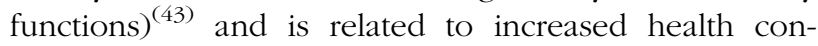
sciousness ${ }^{(19,44)}$. Women are also known to have a better diet because they attach more importance to their weight and have better knowledge about healthy diet ${ }^{(38,45)}$. Moreover, men eat more meat and less F\&V. As previously shown by many studies, high alcohol consumption and low educational level are often associated with poor dietary quality ${ }^{(46,47)}$. Low educational level induces difficulties in understanding information about health and nutrition. Former smokers are also inclined to adopt a better diet because subjects may have modified their lifestyle, including dietary patterns, confirming another study $^{(36)}$. In addition, our results on physical activity are in accordance with previous studies ${ }^{(4,20)}$. High physical activity is associated with a higher VDS. Finally, previous nutritional advice leads to an improved diet ${ }^{(24)}$. BMI was not found as an explanatory factor, but this FFQ evaluates the quality and not the quantity of food intakes. Furthermore, using this FFQ, snack intake was not taken into account. Most of the explanatory factors found for the VDS in the present study are similar to many others that studied non-specific diets ${ }^{(20,36)}$.

The last interesting contribution of our study concerned the subjects' acceptance of dietary assessment, which was found to be very high. This invites us to extend this type of dietary screening to a larger population.

The present study has some potential limitations. First, it was a monocentric study performed in a GP's office in only one French region, and thus the external validity of our results could be called into question. It should be kept in mind that the present study tried to show the interest of such a questionnaire in clinical practice and not to define the whole diet of the French population. Regarding the external validity of our results, it is important to note that the city where the GP's office is located is semi-rural. In this type of city, $20-40 \%$ of the population work in urban areas and the rest work in rural areas. Thus, the differences in dietary patterns between rural and urban areas were limited $^{(48,49)}$. Although the present study was conducted in France, we could suppose that this useful questionnaire is also applicable to other Western countries because it evaluates specific food groups which are consumed in most other Western countries ${ }^{(8)}$. Second, the VDS score value we used to consider the diet as 'favourable' or 'risky' was based on the results of previous studies ${ }^{(16,18)}$ and the roles of food groups were based on the literature. It is important, however, to point out that no study has determined a clinical cut-off using the VDS through a prospective cohort study. Thus, it cannot be ascertained that a 'favourable' diet means a 'low-risk' diet and a 'risky' diet means a 'high-risk' diet. This issue needs to be addressed in order to determine potential relationships between different VDS score values and the risk for developing CVD. As an initial and essential step, the present study performed in a GP's office, together with the results of previous studies using the FFQ in vascular patients, showed that the questionnaire used was an objective, rapid and easy tool to assess dietary pattern in a somewhat important subject cohort. This now opens new perspectives to conduct a prospective cohort study.

\section{Conclusion}

The present study showed that a simple dietary assessment in clinical practice could be performed for prevention of VD due to atherosclerosis. The VDS gives, for each subject, rapid and objective nutritional information, which can help GP or physicians to give advice to subjects. Different factors were associated with poor vascular diet as age, gender, physical activity, educational status, previous nutritional advice and alcohol consumption. Factors that influence the VDS have to be taken into account for the nutrition health programme. Such dietary evaluation is well accepted by the population. Then, the battle against this modifiable risk factor, poor diet, must be carried out in order to reduce VD and the cost of these diseases.

\section{Acknowledgements}

The authors declare that there is no source of funding/ conflict of interest to express. All the authors had full access to all the data in the study and take responsibility for the integrity and the accuracy of the data. G.M. performed the statistical analysis. G.M. and M.C. contributed to the conception and design, analysis and interpretation of the data, have done the critical revision of the manuscript for important intellectual content and supervised the study. M.C. and J.-P.D.B helped the data acquisition; G.M., M.C. and M.Z. contributed to the drafting of the manuscript; G.M., M.C., M.Z. and J.-P.D.B provided administrative, technical or material support. 


\section{References}

1. Leal J, Luengo-Fernandez R, Gray A et al. (2006) Economic burden of cardiovascular diseases in the enlarged European Union. Eur Heart J 27, 1610-1619.

2. Fung TT, Rexrode KM, Mantzoros CS et al. (2009) Mediterranean diet and incidence of and mortality from coronary heart disease and stroke in women. Circulation 119, 1093-1100.

3. Chiuve SE, Rexrode KM, Spiegelman D et al. (2008) Primary prevention of stroke by healthy lifestyle. Circulation 118, 947-954.

4. Chiuve SE, McCullough ML, Sacks FM et al. (2006) Healthy lifestyle factors in the primary prevention of coronary heart disease among men: benefits among users and nonusers of lipid-lowering and antihypertensive medications. Circulation 114, 160-167.

5. Knoops KT, de Groot LC, Kromhout D et al. (2004) Mediterranean diet, lifestyle factors, and 10-year mortality in elderly European men and women: the HALE project. JAMA 292, 1433-1439.

6. Kromhout D, Menotti A, Bloemberg B et al. (1995) Dietary saturated and trans fatty acids and cholesterol and 25-year mortality from coronary heart disease: the Seven Countries Study. Prev Med 24, 308-315.

7. Keys A, Menotti A, Aravanis C et al. (1984) The seven countries study: 2,289 deaths in 15 years. Prev Med 13, 141-154.

8. Iqbal R, Anand S, Ounpuu S et al. (2008) Dietary patterns and the risk of acute myocardial infarction in 52 countries: results of the INTERHEART study. Circulation $\mathbf{1 1 8}$, 1929-1937.

9. Mead A, Atkinson G, Albin D et al. (2006) Dietetic guidelines on food and nutrition in the secondary prevention of cardiovascular disease - evidence from systematic reviews of randomized controlled trials. J Hum Nutr Diet 19, 401-419.

10. Mozaffarian D, Micha R \& Wallace S (2010) Effects on coronary heart disease of increasing polyunsaturated fat in place of saturated fat: a systematic review and metaanalysis of randomized controlled trials. PLoS Med 7, e1000252.

11. Fung TT, Stampfer MJ, Manson JE et al. (2004) Prospective study of major dietary patterns and stroke risk in women. Stroke 35, 2014-2019.

12. Lane JS, Magno CP, Lane KT et al. (2008) Nutrition impacts the prevalence of peripheral arterial disease in the United States. J Vasc Surg 48, 897-904.

13. Kahn R, Robertson RM, Smith R et al. (2008) The impact of prevention on reducing the burden of cardiovascular disease. Circulation 118, 576-585.

14. Wood D, De Backer G, Faergeman O et al. (1998) Prevention of coronary heart disease in clinical practice: recommendations of the Second Joint Task Force of European and other Societies on Coronary Prevention. Atherosclerosis 140, 199-270.

15. Svilaas A, Strom EC, Svilaas T et al. (2002) Reproducibility and validity of a short food questionnaire for the assessment of dietary habits. Nutr Metab Cardiovasc Dis 12, 60-70.

16. Laviolle B, Froger-Bompas C, Guillo P et al. (2005) Relative validity and reproducibility of a 14-item semiquantitative food frequency questionnaire for cardiovascular prevention. Eur J Cardiovasc Prev Rehabil 12, 587-595.

17. Carsin M \& Mahe G (2010) Why should vascular patients have a dietary assessment? J Mal Vasc 35, 17-22.

18. Mahé G, Ronzière T, Laviolle B et al. (2010) An unfavorable dietary pattern is associated with symptomatic ischemic stroke and carotid atherosclerosis. J Vasc Surg (Epublication ahead of print version).
19. Naska A, Fouskakis D, Oikonomou E et al. (2006) Dietary patterns and their socio-demographic determinants in 10 European countries: data from the DAFNE databank. Eur J Clin Nutr 60, 181-190.

20. Drewnowski A, Fiddler EC, Dauchet L et al. (2009) Diet quality measures and cardiovascular risk factors in France: applying the healthy eating index to the SU.VI.MAX study. J Am Coll Nutr 28, 22-29.

21. Drewnowski A \& Shultz JM (2001) Impact of aging on eating behaviors, food choices, nutrition, and health status. J Nutr Health Aging 5, 75-79.

22. Estaquio C, Druesne-Pecollo N, Latino-Martel $\mathrm{P}$ et al. (2008) Socioeconomic differences in fruit and vegetable consumption among middle-aged French adults: adherence to the 5 A Day recommendation. J Am Diet Assoc 108, 2021-2030.

23. Trichopoulou A, Costacou T, Bamia C et al. (2003) Adherence to a Mediterranean diet and survival in a Greek population. N Engl J Med 348, 2599-2608.

24. Froger-Bompas C, Laviolle B, Guillo P et al. (2009) Sustained positive impact of a coronary rehabilitation programme on adherence to dietary recommendations. Arch Cardiovasc Dis 102, 97-104.

25. Suits DB (1957) Use of dummy variables in regression equations. J Am Stat Assoc 52, 548-551.

26. Sun GW, Shook TL \& Kay GL (1996) Inappropriate use of bivariable analysis to screen risk factors for use in multivariable analysis. J Clin Epidemiol 49, 907-916.

27. Harrell FE Jr, Lee KL, Califf RM et al. (1984) Regression modelling strategies for improved prognostic prediction. Stat Med 3, 143-152.

28. Kennedy ET, Ohls J, Carlson S et al. (1995) The Healthy Eating Index: design and applications. J Am Diet Assoc 95, 1103-1108.

29. McCullough ML \& Willett WC (2006) Evaluating adherence to recommended diets in adults: the Alternate Healthy Eating Index. Public Health Nutr 9, 152-157.

30. Prattala R, Paalanen L, Grinberga D et al. (2007) Gender differences in the consumption of meat, fruit and vegetables are similar in Finland and the Baltic countries. Eur J Public Health 17, 520-525.

31. Martin A (2008) Apports Nutritionnels Conseillés Pour la Population Française. Etude Individuelle Nationale sur les Consommations Alimentaires 2006-2007. Paris: Technique et Documentation.

32. Hercberg S, Chat-Yung S \& Chaulia M (2008) The French National Nutrition and Health Program: 2001-2006-2010. Int J Public Health 53, 68-77.

33. Fung TT, Chiuve SE, McCullough ML et al. (2008) Adherence to a DASH-style diet and risk of coronary heart disease and stroke in women. Arch Intern Med 168, $713-720$

34. He K, Rimm EB, Merchant A et al. (2002) Fish consumption and risk of stroke in men. JAMA 288, 3130-3136.

35. Castetbon K, Vernay M, Malon A et al. (2009) Dietary intake, physical activity and nutritional status in adults: the French nutrition and health survey (ENNS, 2006-2007). Br J Nutr 102, 733-743.

36. Estaquio C, Kesse-Guyot E, Deschamps V et al. (2009) Adherence to the French Programme National Nutrition Santé Guideline Score is associated with better nutrient intake and nutritional status. J Am Diet Assoc 109, 1031-1041.

37. Martin A (2001) Apports nutritionnels conseillés pour la population française, 3ème ed. Paris: Tec et Doc Lavoisier.

38. Westenhoefer J (2005) Age and gender dependent profile of food choice. Forum Nutr 57, 44-51.

39. Inelmen EM, Toffanello ED, Enzi G et al. (2008) Differences in dietary patterns between older and younger obese and overweight outpatients. J Nutr Health Aging 12, 3-8. 
40. Volatier JL \& Verger P (1999) Recent national French food and nutrient intake data. Br J Nutr 81, Suppl. 2, S57-S59.

41. Ribas-Barba L, Serra-Majem L, Salvador G et al. (2007) Trends in dietary habits and food consumption in Catalonia, Spain (1992-2003). Public Health Nutr 10, 1340-1353.

42. Smith KJ, McNaughton SA, Gall SL et al. (2009) Takeaway food consumption and its associations with diet quality and abdominal obesity: a cross-sectional study of young adults. Int J Behav Nutr Phys Act 6, 29.

43. Chatard-Pannetier A, Rousset S, Bonin D et al. (2004) Nutritional knowledge and concerns about meat of elderly French people in the aftermath of the crisis over BSE and foot-and-mouth. Appetite 42, 175-183.

44. Johansson L, Thelle DS, Solvoll K et al. (1999) Healthy dietary habits in relation to social determinants and lifestyle factors. Br J Nutr 81, 211-220.
45. De Vriendt T, Matthys C, Verbeke W et al. (2009) Determinants of nutrition knowledge in young and middle-aged Belgian women and the association with their dietary behaviour. Appetite 52, 788-792.

46. Agudo A \& Pera G (1999) Vegetable and fruit consumption associated with anthropometric, dietary and lifestyle factors in Spain. EPIC Group of Spain. European Prospective Investigation into Cancer. Public Health Nutr 2, 263-271.

47. Padrao P, Lunet N, Santos AC et al. (2007) Smoking, alcohol, and dietary choices: evidence from the Portuguese National Health Survey. BMC Public Health 7, 138.

48. Holcomb CA (1995) Positive influence of age and education on food consumption and nutrient intakes of older women living alone. J Am Diet Assoc 95, 1381-1386.

49. Scali J, Richard A \& Gerber M (2001) Diet profiles in a population sample from Mediterranean southern France. Public Health Nutr 4, 173-182. 